\title{
PERIOPERATIVE CHEMOTHERAPY IN LOCALLY ADVANCED GASTRIC CANCER
}

\author{
Thales Paulo BATISTA, Candice Amorim de Araújo Lima SANTOS, and \\ Gustavo Fernandes Godoy ALMEIDA
}

\begin{abstract}
Gastric cancer is one of the most common cancers and a main cause of cancer-related death worldwide, since the majority of patients suffering of this malignancy are usually faced with a poor prognosis due to diagnosis at later stages. In order to improve treatment outcomes, the association of surgery with chemo and/or radiotherapy (multimodal therapy) has become the standard treatment for locally advanced stages. However, despite several treatment options currently available for management of these tumors, perioperative chemotherapy has been mainly accepted for the comprehensive therapeutic strategy including an appropriated D2-gastrectomy. This manuscript presents a (nonsystematic) critical review about the use of perioperative chemotherapy, with a special focus on the drugs delivery.
\end{abstract}

HEADINGS - Stomach neoplasms. Antineoplastic agents. Combined modality therapy. Drug therapy.

\section{INTRODUCTION}

Gastric cancer (i.e.: gastric adenocarcinoma) is one of the most common cancers and a main cause of cancer-related death worldwide, accounting for $10 \%$ of all oncological deaths ${ }^{(29)}$. Unfortunately, only $10 \%$ to $20 \%$ of tumors are diagnosed early enough to be candidates for curative resection in Western countries $^{(20)}$. In Brazil, 20,000 new cases are estimated to occur in $2012 / 2013^{(10)}$ with only about $10 \%$ staged as early tumors ${ }^{(39)}$. Herein, these rates may be as low as $3.8 \%-5.2 \%$ in some North and Northeast regions ${ }^{(11,60)}$, where $78 \%$ of patients are diagnosed with TNM stages III or IV ${ }^{(3,60)}$. In these settings, gastric cancer patients are usually faced with a very poor prognosis and mortality rates remains quite $\operatorname{high}^{(24,64)}$.

Surgery remains the mainstay for cure and should be considered for all patients with potentially resectable gastric cancer who are fit for a major surgery. However, despite surgery alone usually provides a favorable prognosis in early gastric cancer, most locally advanced tumors eventually recur even after a complete resection (R0). Therefore, the association of surgery with chemo and/or radiotherapy (multimodal therapy) has become the established treatment for locally advanced stages.

Currently, several acceptable perioperative chemotherapy or chemoradiation regimens are available for a multimodal management of locally advanced gastric cancers. However, despite 5FU-based chemoradiation has been considered standard for many years in the adjuvant setting ${ }^{(36)}$, perioperative chemotherapy without radiation has been nowadays mainly accepted for the comprehensive therapeutic strategy including an appropriated D2-gastrectomy ${ }^{(7)}$. This current study provides a (nonsystematic) critical review about the use of perioperative chemotherapy, with a special focus on the drugs delivery.

\section{CHEMOTHERAPY APPROACHES}

\section{Adjuvant chemotherapy}

By the observation of chemosensitivity in metastatic gastric cancers, many randomized trials have investigated the role of adjuvant chemotherapy in an attempt to increase cure rates after surgery for resectable gastric cancers ${ }^{(4,6,9,14,18,19,32,40-42,49-51)}$. (Table 1) Depite early trials presented negative results, possibly due to the use of old (and less effective) cytotoxic regimens; two main Asian trials were able to demonstrate survival benefit favoring the experimental arm of surgery plus adjuvant chemotherapy ${ }^{(6,50,51)}$.

In 2007, the first of these trials (ACTS-GC) ${ }^{(50)}$ tested the use of S-1 in Japanese patients with stage II or III gastric cancer who underwent D2-gastrectomy. This drug is an orally active combination of tegafur (a prodrug that is converted by cells to fluorouracil), gimeracil (an inhibitor of dihydropyrimidine dehydrogenase, which degrades fluorouracil), and oteracil (which inhibits the phosphorylation of fluorouracil in the gastrointestinal tract, thereby reducing the gastrointestinal toxic effects of fluorouracil). This trial

Declared conflict of interest of all authors: non

Faculdade Pernambucana de Saúde, Instituto de Medicina Integral Professor Fernando Figueira - FPS/IMIP

Correspondence: Thales P. Batista. A. Boa Viagem, 5212, ap. 1515 - 51030-000, Recife, PE, Brasil. E-mail: t.paulo@bol.com.br 
TABLE 1. Summary of main phase III trials published in the last decade comparing adjuvant chemotherapy vs. surgery

\begin{tabular}{|c|c|c|c|c|c|c|}
\hline Trial & $\mathrm{n}$ & Regimen & Overral survival & HR $(95 \% \mathrm{CI})$ & Disease-free survival & HR $(95 \% \mathrm{CI})$ \\
\hline Bajetta et al..$^{(4)}$ & 274 & $\mathrm{EAP} / \mathrm{FL}$ & $52 \%$ vs $48 \%(5 y)$ & $0,93(0.65-1.34)$ & $49 \%$ vs $44 \%(5 y)$ & $0.83(0.59-1.17)$ \\
\hline Nashimoto et al. ${ }^{(41)}$ & 252 & $\mathrm{MFC} / \mathrm{F}$ & $91.2 \%$ vs $86.1 \%(5 y)$ & - & $88.8 \%$ vs $83.7 \%(5 y)$ & - \\
\hline Chipponi et al. ${ }^{(14)}$ & 205 & LFC & $39 \%$ vs $39 \%(5 y)$ & - & - & - \\
\hline Popiela et al. ${ }^{(49)}$ & 156 & FAM & $30 \%$ vs $15,2 \%(10 y)$ & $0,82(0,65-1,01)$ & - & - \\
\hline Bouché et al. ${ }^{(9)}$ & 260 & $\mathrm{CF}$ & $46.6 \%$ vs $41.9 \%(5 y)$ & $0,74(0.54-1.02)$ & $47.6 \%$ vs $39.8 \%(5 y)$ & $0.70(0.51-0.97)$ \\
\hline Nitti et al..$^{(42)}$ & 397 & FAMTX or FEMTX & $43 \%$ vs $44 \%(5 y)$ & $0.98(0.72-1.24)$ & $41 \%$ vs $42 \%(5 y)$ & $0.98(0.72-1.24)$ \\
\hline De Vita et al. ${ }^{(18)}$ & 228 & ELFE & $48 \%$ vs $43.5 \%(5 y)$ & $0.91(0.69-1,21)$ & $44 \%$ vs $39 \%(5 y)$ & $0.88(0.78-0.91)$ \\
\hline Nakajima et al..$^{(40)}$ & 190 & UFT & $86 \%$ vs $73 \%(5 y)$ & $0.48(0.26-0.89)$ & $85 \%$ vs $68 \%(5 y)$ & $0.44(0.25-0.79)$ \\
\hline ACTS-GC & 1059 & S1 & $71.7 \%$ vs $61.1 \%(5 y)$ & $0.66(0.54-0.82)$ & $65.4 \%$ vs $53.1 \%(5 y)$ & $0.65(0.53-0.79)$ \\
\hline Di Costanzo et al..$^{(19)}$ & 258 & PELF & $47.6 \%$ vs $48.7 \%(5 y)$ & $0.90(0.64-1.26)$ & $42.3 \%$ vs $41.6 \%(5 y)$ & $0.92(0.65-1.27)$ \\
\hline Kulig et al. ${ }^{(32)}$ & 309 & EAP & $47 \%$ vs $40 \%(5 y)$ & $0.74(0.54-1.02)$ & - & - \\
\hline CLASSIC & 1035 & XELOX & $83 \%$ vs $78 \%(3 y)$ & $0.72(0.52-1.00)$ & $74 \%$ vs $59 \%(3 y)$ & $0.56(0.44-0.72)$ \\
\hline
\end{tabular}

Footnote: HR: hazard ratio; CI: confidence interval; EAP/FL: etoposide, adriamycin and cisplatin followed by fluorouracil and folinic acid; MFC/F: mitomycin, fluorouracil and cytarabine followed by fluorouracil; LFC: folinic acid, fluorouracil and cisplatin; FAM: fluorouracil, adriamycin and mitomycin; CF: fluorouracil and cisplatin; FAMTX/FEMTX: fluorouracil, adriamycin or epirubicin and methotrexate with leucovorin rescue; ELFE: epirubicin, leucovorin, fluorouracil and etoposide; UFT: uracil-tegafur; S-1: tegafur/gimeracil/oteracil; PELF: cisplatin, epirubicin, leucovorin and fluorouracil; EAP: etoposide, adriamycin and cisplatin; XELOX: capecitabine plus oxaliplatin

accrued 1,059 patients and was discontinued earlier because the experimental arm had achieved higher overall $(80.1 \%$ vs $70.1 \%)$ and relapse-free $(72.2 \%$ vs $59.6 \%)$-year survival rates than the surgery-only group. The hazard ratio for death (HR $0.68 ; 95 \%$ CI, 0.52 to $0.87 ; P=0.003$ ) and relapse (HR $0.62 ; 95 \% \mathrm{CI}, 0.50$ to $0.77 ; P<0.001)$ favored the $\mathrm{S}-1$ group, whereas the longer follow-up corroborated these results. The overall 5 -year survival rate was $71.7 \%$ in the $\mathrm{S}-1$ group vs. $61.1 \%$ in the surgery-only group $(\mathrm{HR}=0.669 ; 95 \% \mathrm{CI}, 0.540$ to 0.828 ), and the relapse-free survival was $65.4 \%$ vs $53.1 \%$ $(\mathrm{HR}=0.653 ; 95 \% \mathrm{CI}, 0.537$ to 0.793$)$, confirming the benefit of adjuvant chemotherapy in stage II or III gastric cancer patients who have undergone D2-gastrectomy ${ }^{(51)}$.

The second Asian study, Capecitabine and Oxaliplatin Adjuvant Study in Stomach Cancer (CLASSIC) ${ }^{(6)}$, recently also presented the role of adjuvant chemotherapy after D2 gastrectomy in stage II or III gastric cancer patients. After a median follow-up of 34 months, the chemo group had a higher rate of overall ( $83 \%$ vs $78 \%$ ) and relapse-free (74\% vs $59 \%$ ) 3 -year survival than the surgery-only group. The hazard ratio was $0.72(95 \% \mathrm{CI}, 0.52$ to $1.00 ; P<0.0001)$ for death and $0.56(95 \% \mathrm{CI}, 0.44$ to $0.72 ; P<0.0001)$ for relapse, favoring the use of postoperative chemotherapy, including consistent benefit for all disease stages. With these findings, the authors suggested adjuvant capecitabine and oxaliplatin as a new treatment option for patients with resectable disease.

Many meta-analyses also have confirmed the benefit of postoperative chemotherapy on gastric cancer patients ${ }^{(23,26-28}$, 30, 35, 43, 44,47,56,63). In the last of these ${ }^{(23)}$, The Global Advanced/ Adjuvant Stomach Tumor Research through the International Collaboration (GASTRIC) group conducted an individual patient data analysis and found a modest but significant survival advantage for postoperative chemotherapy, based on data available from 17 trials including 3838 patients with a median follow-up exceeding 7 years. Accordingly, adjuvant chemotherapy was associated with a statistically significant benefit in terms of overall (HR, $0.82 ; 95 \%$ CI, 0.76 to 0.90 ;
$P<0.001)$ and disease-free survival (HR, 0.82; 95\% CI, 0.75 to $0.90 ; P<0.001)$. An absolute improvement of about $6 \%$ in overall survival was observed after 5-year, which was sustained at 10 -year.

\section{Perioperative chemotherapy (adjuvant and neoadjuvant)}

Two trials - the Medical Research Council Adjuvant Gastric Infusional Chemotherapy (MAGIC) ${ }^{(16)}$ and the French Action Clinique Coordonnées en Cancéologie Digestive (ACCORD-07) ${ }^{(62)}$ - have found that perioperative chemotherapy provided better outcomes than surgery alone for gastric cancer patients. These trials supported the use of chemotherapy in a pre- and postoperative manner. These studies have changed the clinical practice across Europe after a significant improvement in survival has been reported. Together, they are currently the cornerstone references to support the use of perioperative chemotherapy for locally advanced gastric cancer patients.

In the MAGIC trial ${ }^{(16)}, 503$ patients with resectable adenocarcinoma of the stomach, esophagogastric junction, or lower esophagus were randomly assigned to either perioperative chemotherapy plus surgery $(\mathrm{n}=250)$ or surgery alone $(n=253)$. Chemotherapy consisted of three preoperative and three postoperative cycles of intravenous epirubicin $(50 \mathrm{mg}$ per square meter of body-surface area) and cisplatin $(60 \mathrm{mg}$ per square meter) on day 1 , and a continuous intravenous infusion of fluorouracil ( $200 \mathrm{mg}$ per square meter per day) for 21 days.

When compared with the surgery-only group, the perioperative chemotherapy group had a significantly higher likelihood of progression-free $(\mathrm{HR}=0.66 ; 95 \% \mathrm{CI}=$ $0.53-0.81 ; P<0.001)$ and overall survival $(\mathrm{HR}=0.75 ; 95 \%$ $\mathrm{CI}=0.60-0.93 ; P=0.009$ ). Curative resections were more frequent in the chemotherapy plus surgery arm, compared to surgery alone $(P=0.03)$. Postoperative complications rates were similar in the two groups ( $45.7 \%$ vs $45.3 \%)$, as 
well as 30 -day mortality rate $(5.6 \%$ vs $5.9 \%)$ and the median hospital stay (13 days in both groups). A total of 215 patients completed the preoperative protocol $(90.7 \%$ of planned protocol) and 209 of them proceeded to surgery; whereas $65.6 \%$ subsequently began postoperative chemotherapy but only 104 of 250 patients $(41.6 \%)$ completed all six cycles of chemotherapy. Pathological findings included smaller diameter of the resected tumor $(3 \mathrm{~cm}$ vs $5 \mathrm{~cm}$; $P<0.001)$, a greater proportion of stage $\mathrm{T} 1 / \mathrm{T} 2$ tumors $(P=0.002)$, and significant less advanced nodal disease $(P=0.01)$ in the chemotherapy arm.

Thereafter, results from the ACCORD-07 trial ${ }^{(62)}$ also supported the MAGIC trial. In this study, 224 patients with resectable gastric or gastro-oesophageal junction adenocarcinoma were randomly assigned to either perioperative chemotherapy plus surgery $(n=113)$ or surgery alone $(n=111)$. Chemotherapy consisted of two-three preoperative cycles of intravenous cisplatin $\left(100 \mathrm{mg} / \mathrm{m}^{2}\right)$ on day 1 , and a continuous intravenous infusion of fluorouracil $\left(800 \mathrm{mg} / \mathrm{m}^{2} / \mathrm{d}\right)$ for 5 consecutive days (days 1 to 5) every 28 days; and three-four cycles of adjuvant chemotherapy were given to those in the latter group who responded to preoperative chemotherapy or had stable disease, accounting for a total of six cycles.

Compared to surgery-alone arm, the perioperative chemotherapy arm had a significantly higher overall survival (HR, $0.69 ; 95 \% \mathrm{CI}, 0.50$ to $0.95 ; P=0.02$ ) and disease free survival $(\mathrm{HR}=0.65 ; 95 \% \mathrm{CI}, 0.48$ to $0.89 ; P=0.003)$. The $\mathrm{R} 0$ resection rate after perioperative therapy was significantly improved compared to surgical resection alone $(P=0.04)$, and postoperative morbidity and mortality rates were similar in the two groups $(25.7 \%$ vs $19.1 \%$ and $4.6 \%$ vs $4.5 \%$; respectively). The authors also observed a downsizing for tumor and nodal stages in the mutimodal treatment arm, but only $50 \%$ of the patients were able to restart postoperative chemotherapy and just $23 \%$ of them completed the protocol.

Table 2 summarizes the main improvements resulted from the MAGIC ${ }^{(16)}$ and ACCORD-07(62) trials. Both studies demonstrated that perioperative chemotherapy with a regimen of either, ECF or CF, improves overall and progression-free survival among patients with gastric cancers compared to surgery alone, with an estimated improvement of $13 \%-14 \%$ in the 5 -year survival rate and a $25 \%-31 \%$ reduction in the risk of death, despite fewer than $50 \%$ of patients received postoperative chemotherapy in both trials.

TABLE 2. Summary of main improvements from MAGIC and ACCORD-07 trials

\begin{tabular}{lcccc}
\hline \multirow{2}{*}{ End-point } & \multicolumn{2}{c}{ MAGIC } & \multicolumn{2}{c}{ ACCORD-07 } \\
\cline { 2 - 5 } & Multimodal & Surgical & Multimodal & Surgical \\
\hline 5-year Survival & $36.3 \%$ & $23 \%$ & $38 \%$ & $24 \%$ \\
Curative or R0 Rates & $79.3 \%$ & $70.3 \%$ & $87 \%$ & $74 \%$ \\
pT Rates & & & & \\
T1/T2 & $51.7 \%$ & $36.8 \%$ & $39 \%$ & $32 \%$ \\
T3/T4 & $48.3 \%$ & $63.2 \%$ & $58 \%$ & $68 \%$ \\
pN0 Rates & $31 \%$ & $26.9 \%$ & $33 \%$ & $20 \%$ \\
\hline
\end{tabular}

\section{Neoadjuvant chemotherapy}

There is currently no phase III study supporting a purely neoadjuvant strategy for resectable gastric cancer. The European EORTC 40954 phase III trial ${ }^{(52)}$ was designed with end-points analyzing the efficacy of preoperative treatments to be demonstrated. However, the adoption of strict selection criteria made patient selection so difficult that the study was prematurely terminated. This trial tested a combination of cisplatin, 5-FU and folinic acid (PLF) delivered for two cycles before surgery compared to surgery alone. Study protocol was closed due to poor recruitment and, although an increased rate of R0 resections has been reported $(81.9 \%$ vs $66.7 \%$, $P=0.036$ ), no significant effect on survival was demonstrated (HR $0.84,95 \%$ CI $0.52-1.35 ; P=0.466$ ).

Previously, the Dutch FAMTX trial ${ }^{(25,54)}$ also had attempted to address this important issue but failed to provide any definitive answer. Similarly, this study was prematurely closed after 59 patients have been enrolled, when an interim analysis showed inadequate rates of curative resection in the chemotherapy group. Herein, patients were randomized to receive four courses of chemotherapy using 5-fluorouracil, doxorubicin and methotrexate (FAMTX) prior to surgery or to undergo surgery alone. Nevertheless, resectability rates were equal for both groups and despite a complete or partial response has been registered in $32 \%$ of the FAMTX group, the median survival since randomization was only 18 months in the FAMTX group versus 30 months in the surgery alone $\operatorname{arm}(P=0.17)$.

\section{DISCUSSION}

Patients with gastric cancer should undergo a pre-treatment multidisciplinary assessment to determine the best plan of care and, in addition to a D2-gastrectomy, all patients with locally advanced disease should be considered for some neoadjuvant and/or adjuvant therapy. The challenge now is to select the appropriated combination for each clinical presentation whereas an optimal approach has not been established yet.

Most of limitation in worldwide acceptance of adjuvant chemotherapy alone lies on the disparities in Eastern vs Western approaches to the management of gastric cancer ${ }^{(45,46)}$, specially regarding some confounding results for the use of S-1 chemotherapy in non-Asian patients. However, comparison of the pharmacokinetics and pharmacodynamics of S-1 between Caucasian and East Asian patients yields no significant difference in 5-fluorouracil exposure between them ${ }^{(15)}$ and some clinical studies have demonstrated that either the most common oral fluoropyrimidines, namely S- 1 and capecitabine, present similar efficacy and safety, and appears to be equally applicable for both populations ${ }^{(1,53,61)}$. Moreover, the GASTRIC group report was based on individual patient data meta-analysis, which is the main reliable means to provide an exhaustive and unbiased summary of the available evidence on a clinical question of interest and complete large well-conducted trials. It included most of the items deemed necessary for a well-conducted meta-analysis except a list of 
excluded studies, which few meta-analyses provide, and an assessment of the likelihood of publication bias. There was no significant heterogeneity for overall survival across trials $(P=0.52)$ or the four regimens of chemotherapy studied $(P=0.13)$. This meta-analysis demonstrated that there is a survival advantage in using postoperative chemotherapy to treat gastric cancer patients ${ }^{(23)}$.

Another major concern in the perioperative management of gastric cancer is whether the preoperative vs postoperative chemotherapy mainly contribute to improve patients survival. The SWS-SAKK 43/99 trial $^{(8)}$ tried to address this relevant issue, but it was prematurely stopped due to insufficient accrual and failed to provide a definitive answer. Herein, the authors confirmed the difficulties in administering intensive adjuvant chemotherapy in gastric cancer patients (four cycles of docetaxel, cisplatin and 5-fluorouracil, either preoperatively or postoperatively), but this study did not provide information on efficacy because of early discontinuation. Presently, the design of ongoing docetaxel/oxaliplatin/S-1 regimen as neoadjuvant chemotherapy in advanced gastric cancer (PRODIGY) has the potential to collaborate to the theorical advantages of perioperative (pre- and postoperative) chemotherapy over adjuvant chemotherapy alone. This study was designed to compare differences in progression free survival between these two established practices (NCT01515748). Currently, there is no definite evidence supporting one approach over the other.

The difficulty of delivering adjuvant strategies to the patient following major surgery suggests that chemotherapy may be more safely administered preoperatively in patients suffering of gastric cancer ${ }^{(8,12,16,21,62)}$. Theoretical benefits of neoadjuvant approach is that chemotherapy delivery may be more efficient if given prior to surgical disruption of tumor vasculature and also concerns micrometastasis that are undetectable at the start of treatment and could remain untreated for several weeks when the surgery-first strategy is selected. Adittionally, preoperative chemotherapy can be used to evaluate tumor chemosensitivity to cytotoxic medications and may result in downstaging of the tumors, which consequently may improve the curative resection rate in patients with advanced $\mathrm{T}$ and $\mathrm{N}$ stages. Finally, this approach may also improve patient tolerance since performance status is usually negatively impacted by surgery-related morbidity and symptoms ${ }^{(18,33,52)}$.

Despite neoadjuvant chemotherapy has drawn more attention in the current multidisciplinary treatment model ${ }^{(13,33)}$ and appears not associated with increased postoperative mortality ${ }^{(16,34,62)}$, lack of response to this approach may delay curative surgery and chemotherapy-induced toxicity may also increase surgical complications, specially after a D2-dissection ${ }^{(2,33,52)}$.

Whereas preoperative chemotherapy is an effective manner to increase $\mathrm{R} 0$ rates $^{(16,62,33,48)}$ and whether these findings are associated with improved overall survival requires further studies ${ }^{(13,52)}$. Up to now, neoadjuvant chemotherapy appears to improve outcomes only if added to some adjuvant approach $^{(13)}$, whereas the low rates of pathological complete response (even after more effective chemotherapy regimens) ${ }^{(8,22)}$ and the possibility of tumor cells dissemination during surgical maneuvers ${ }^{(37,38)}$ suggest the need for maintenance of some adjuvant component of treatment in order to enhance results from a comprehensive management.

On the other hand, the perioperative approach, including pre- and pos-operative chemotherapy, seems to be a very attractive treatment option for patients with locally-advanced gastric carcinoma due to the possible sum of the benefits of both approaches. Additionally, since the publication of MAGIC ${ }^{(16)}$ and ACCORD-0 $7^{(62)}$ trials, some changes in chemotherapy regimens have been proposed. Lessons from management of metastatic disease has pointed that replacement of cisplatin by oxaliplatin and/or fluorouracil by capecitabine does not impair the treatment efficacy ${ }^{(17,55)}$ but may improve delivery convenience $^{(57)}$ and offer a different toxicity profile ${ }^{(17,55)}$. Also, incorporation of docetaxel, as in DCF, or other active drug(s), has also become an atractive option for selected patients in good condition ${ }^{(31,58,59)}$, and represents currently reasonable treatment options in the perioperative settings ${ }^{(22)}$ (Figure 1).

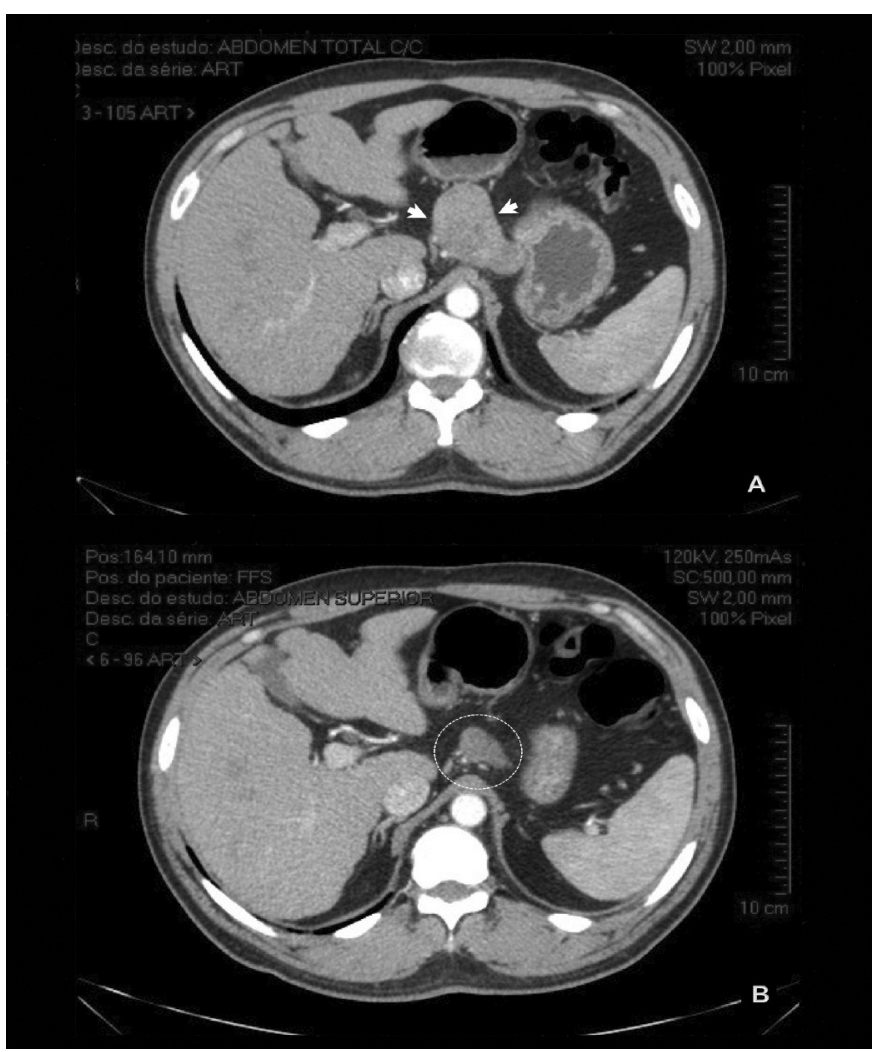

FIGURE 1. Axial contrast-enhanced CT-scan before (A) and after (B) the neoadjuvant component of treatment with perioperative chemotherapy (DCF - docetaxel, cisplatin and 5FU). Note the bulky lymph node metastasis at lesser curve of stomach surrounding the celiac axis (arrows, A), and its down-sizing after the neoadjuvant chemotherapy regimen (circle, B). This patient underwent a total D2-gastrectomy after staging laparoscopy (COP0) and 4 cycles of neoadjuvant chemotherapy, but the adjuvant treatment was not completely delivered. Because toxicity, patient refuse to receive the last of the two planned postoperative cycles of chemotherapy. The pathological exam evidenced a pT1 tumor with no further evidence of cancer spread to regional lymph nodes (N0). (Pictures from authors' own archives). 
Finally, multiple biologic agents are currently under investigation for use in gastric cancer and represent a promising strategy also to be explored in the perioperative setting. The addition of these biological agents to the optimal chemotherapy or chemoradiation regimens may achieve further improvements in efficacy. Due to the success of the MAGIC trial in the United Kingdom, the MAGIC-B trial (MRC-ST03) is ongoing to determine the efficacy of adding bevacizumab to adjuvant chemotherapy. (NCT00407186) This European randomized phase III trial will assess the safety and efficacy of neoadjuvant and adjuvant chemotherapy including epirubicin, cisplatin and capecitabine with or without bevacizumab in patients with untreated resectable gastric or gastroesophageal junction cancer. The results of this study may clarify the role of bevacizumab in the perioperative setting. Similarly, on the basis of promising findings from $\mathrm{ToGA}^{(5)}$ and CLASSIC ${ }^{(6)}$ trials, a study of capecitabine and oxaliplatin plus trastuzum$\mathrm{ab}$ after D2-gastrectomy in patients with human epidermal growth factor receptor (HER)-2-positive resectable disease, namely TOXAG (trastuzumab, oxaliplatin, and Xeloda for adjuvant gastric cancer), was recently designed to evaluate the impact of trastuzumab as a perioperative strategy. Results of these trials may open new interesting pathways to upcoming protocols for the use of targeted therapy in perioperative treatment of gastric cancer. Further randomized trials are therefore necessary to explore novel treatment combinations including biologic agents.

\section{CONCLUSIONS}

The scalpel-alone policy for locally advanced gastric cancer is currently over. Adjuvant chemotherapy may be now recommended for patients who have not received perioperative treatments after complete resection of their gastric cancer, especially when a D2 dissection was performed. While there is no clear evidence to utilize neoajuvant chemotherapy alone, the MAGIC and ACCORD-07 trials support the perioperative chemotherapy (neoadjuvant and adjuvant) as a standard approach level $\mathrm{A}$ in the management of resectable locally-advanced adenocarcinoma of stomach, no matter what proximal or distal tumors. However, further effort is still necessary to determine the best treatment plan. A possible and easy way to improve its efficacy is modify the timing of drug delivery by applying most cycles before surgery in order to increase completeness of the protocol. Another promising manner is to combine chemotherapy with biological agents.

Batista TP, Santos CAAL, Almeida GFG. Quimioterapia peri-operatória no tratamento do câncer gástrico localmente avançado. Arq Gastroenterol. 2013,50(3):236-42.

RESUMO - O câncer gástrico representa um dos cânceres mais comuns em todo o mundo e uma importante causa de óbito por causas oncológicas, uma vez que a maioria dos pacientes com esta neoplasia malígna é confrontada com um prognóstico muito ruim em decorrência do diagnóstico comumente tardio. Com o intuito de melhorar os resultados do tratamento, a associação de cirurgia com quimioterapia e/ou radioterapia (terapia multidisciplinar), tornou-se o tratamento padrão para os casos em estádios localmente avançados. Por outro lado, embora diversos regimes de tratamento estejam atualmente disponíveis para o manejo desses tumores, a quimioterapia perioperatória tem recebido maior atenção como estratégia terapêutica quando a abordagem cirúrgica utilizada inclui a dissecção D2 dos linfonodos regionais. Apresenta-se uma revisão crítica (não-sistemática) sobre o uso de quimioterapia perioperatória no tratamento do câncer gástrico localmente avançado.

DESCRITORES - Câncer de estômago. Antineoplásicos. Terapia combinada. 


\section{REFERENCES}

1. Ajani JA, Rodriguez W, Bodoky G, Moiseyenko V, Lichinitser M, Gorbunova V, Vynnychenko I, Garin A, Lang I, Falcon S. Multicenter phase III comparison of cisplatin/S-1 with cisplatin/infusional fluorouracil in advanced gastric or gastroesophageal adenocarcinoma study: the FLAGS trial. J Clin Oncol. 2010;28:1547-53.

2. An JY, Kim KM, Kim YM, Cheong JH, Hyung WJ, Noh SH. Surgical Complications in Gastric Cancer Patients Preoperatively Treated with Chemotherapy: Their Risk Factors and Clinical Relevance. Ann Surg Oncol. 2012;19:2452-8.

3. Arregi MM, Férrer DP, Assis EC, Paiva FD, Sobral LB, André NF, Silva TC [Clinical - epidemiological profile of gastric neoplasms in the cancer Hospital of Ceara's Cancer Institute, from the period 2000-2004]. Rev Bras Cancerol. 2009;55:121-8

4. Bajetta E, Buzzoni R, Mariani L, Beretta E, Bozzetti F, Bordogna G, Aitini E, Fava S, Schieppati G, Pinotti G, Visini M, Ianniello G, Di BM. Adjuvant chemotherapy in gastric cancer: 5 -year results of a randomised study by the Italian Trials in Medical Oncology (ITMO) Group. Ann Oncol. 2002;13:299-307.

5. Bang YJ, Van Cutsem E, Feyereislova A, Chung HC, Shen L, Sawaki A, Lordick F, Ohtsu A, Omuro Y, Satoh T, Aprile G, Kulikov E, Hill J, Lehle M, Rüschoff J, Kang YK; ToGA Trial Investigators. Trastuzumab in combination with chemotherapy versus chemotherapy alone for treatment of HER2-positive advanced gastric or gastro-oesophageal junction cancer (ToGA): a phase 3, open-label, randomised controlled trial. Lancet. 2010.28;376:687-97.

6. Bang YJ, Kim YW, Yang HK, Chung HC, Park YK, Lee KH, Lee KW, Kim YH, Noh SI, Cho JY, Mok YJ, Kim YH, Ji J, Yeh TS, Button P, Sirzén F, Noh SH; CLASSIC trial investigators. Adjuvant capecitabine and oxaliplatin for gastric cancer after D2 gastrectomy (CLASSIC): a phase 3 open-label, randomised controlled trial. Lancet. 2012;379:315-21.

7. Batista TP, Martins MR. Lymph node dissection for gastric cancer: a critical review. Oncology Reviews 2012; 6:e12

8. Biffi R, Fazio N, Luca F, Chiappa A, Andreoni B, Zampino MG, Roth A, Schuller JC, Fiori G, Orsi F, Bonomo G, Crosta C, Huber O. Surgical outcome after docetaxel-based neoadjuvant chemotherapy in locally-advanced gastric cancer. World J Gastroenterol. 2010;16:868-74.

9. Bouché O, Ychou M, Burtin P, Bedenne L, Ducreux M, Lebreton G, Baulieux J, Nordlinger B, Martin C, Seitz JF, Tigaud JM, Echinard E, Stremsdoerfer N, Milan C, Rougier P; Fédération Francophone de Cancérologie Digestive Group. Adjuvant chemotherapy with 5-fluorouracil and cisplatin compared with surgery alone for gastric cancer: 7-year results of the FFCD randomized phase III trial (8801). Ann Oncol. 2005;16:1488-97.

10. Brasil. Ministério da Saúde.[Internet]. Estimation 2012: cancer incidence in Brazil. Rio de Janeiro, National Cancer Institute (INCA), 2011. [cited 2012 May 7]. Available from: http://www.inca.gov.br/estimativa/2012/.

11. Campelo JC, Lima LC. [Clinical and epidemiological profile of early gastric cancer in a Referral Hospital in Teresina, Piauí]. Rev Bras Cancerol. 2012;58:15-20.

12. Cascinu S, Labianca R, Barone C, Santoro A, Carnaghi C, Cassano A, Beretta GD, Catalano V, Bertetto O, Barni S, Frontini L, Aitini E, Rota S, Torri V, Floriani I; Italian Group for the Study of Digestive Tract Cancer, Pozzo C, Rimassa L, Mosconi S, Giordani P, Ardizzoia A, Foa P, Rabbi C, Chiara S, Gasparin G, Nardi M, Mansutti M, Arnoldi E, Piazza E, Cortesi E, Pucci F, Silva RR, Sobrero A, Ravaioli A. Adjuvant treatment of high-risk, radically resected gastric cancer patients with 5-fluorouracil, leucovorin, cisplatin, and epidoxorubicin in a randomized controlled trial. J Natl Cancer Inst. 2007;99:601-7.

13. Chen XZ, Yang K, Liu J, Chen XL, Hu JK. Neoadjuvant plus adjuvant chemotherapy benefits overall survival of locally advanced gastric cancer. World J Gastroenterol. 201117(40):4542-4.

14. Chipponi J, Huguier M, Pezet D, Basso N, Hay JM, Quandalle P, Jaeck D, Fagniez PL, Gainant A. Randomized trial of adjuvant chemotherapy after curative resection for gastric cancer. Am J Surg. 2004;187:440-5.

15. Chuah B, Goh BC, Lee SC, Soong R, Lau F, Mulay M, Dinolfo M, Lim SE, Soo R, Furuie T, Saito K, Zergebel C, Rosen LS. Comparison of the pharmacokinetics and pharmacodynamics of S-1 between Caucasian and East Asian patients. Cancer Sci. 2011;102:478-83

16. Cunningham D, Allum WH, Stenning SP, Thompson JN, Van de Velde CJ, Nicolson M, Scarffe JH, Lofts FJ, Falk SJ, Iveson TJ, Smith DB, Langley RE, Verma M, Weeden S, Chua YJ, MAGIC Trial Participants. Perioperative chemotherapy versus surgery alone for resectable gastroesophageal cancer. N Engl J Med. 2006;355:11-20.

17. Cunningham D, Starling N, Rao S, Iveson T, Nicolson M, Coxon F, Middleton G, Daniel F, Oates J, Norman AR and Kingdom, Upper Gastrointestinal Clinical Studies Group of the National Cancer Research Institute of the United Kingdom. Capecitabine and oxaliplatin for advanced esophagogastric cancer. N Engl J Med 2008;358:36-46.
18. De Vita F, Giuliani F, Galizia G, Belli C, Aurilio G, Santabarbara G, Ciardiello F, Catalano G, Orditura M. Neo-adjuvant and adjuvant chemotherapy of gastric cancer. Ann Oncol. 2007;18 Suppl 6:vi120-3.

19. Di Costanzo F, Gasperoni S, Manzione L, Bisagni G, Labianca R, Bravi S, Cortesi E, Carlini P, Bracci R, Tomao S, Messerini L, Arcangeli A, Torri V, Bilancia D, Floriani I, Tonato M, et al. Adjuvant chemotherapy in completely resected gastric cancer: a randomized phase III trial conducted by GOIRC. J Natl Cancer Inst. 2008;100:388-98.

20. Everett SM, Axon AT. Early gastric cancer in Europe. Gut. 1997;41:142-50.

21. Fazio N, Biffi R, Curigliano G, Lorizzo K, Zampino MG, de Braud F, Chiappa A, Roth A, Goldhirsch A. Re: Adjuvant treatment of high-risk, radically resected gastric cancer patients with 5-fluorouracil, leucovorin, cisplatin, and epidoxorubicin in a randomized controlled trial. J Natl Cancer Inst. 2007;99:1345-6.

22. Ferri LE, Ades S, Alcindor T, Chasen M, Marcus V, Hickeson M, Artho G, Thirlwell MP. Perioperative docetaxel, cisplatin, and 5-fluorouracil (DCF) for locally advanced esophageal and gastric adenocarcinoma: a multicenter phase II trial. Ann Oncol. 2012;23:1512-7.

23. GASTRIC (Global Advanced/Adjuvant Stomach Tumor Research International Collaboration) Group, Paoletti X, Oba K, Burzykowski T, Michiels S, Ohashi Y, Pignon JP, Rougier P, Sakamoto J, Sargent D, Sasako M, Van Cutsem E, Buyse M. Benefit of adjuvant chemotherapy for resectable gastric cancer: a meta-analysis. JAMA. 2010;303:1729-37.

24. Guimarães RM, Muzi CD. Trend of mortality rates for gastric cancer in Brazil and regions in the period of 30 years (1980-2009). Arq Gastroenterol. 2012;49:184-8.

25. Hartgrink HH, van de Velde CJ, Putter H, Songun I, Tesselaar ME, Kranenbarg EK, de Vries JE, Wils JA, van der Bijl J, van Krieken JH; Cooperating Investigators of The Dutch Gastric Cancer Group. Neo-adjuvant chemotherapy for operable gastric cancer: long term results of the Dutch randomised FAMTX trial. Eur J Surg Oncol. 2004;30:643-9.

26. Hu JK, Chen ZX, Zhou ZG, Zhang B, Tian J, Chen JP, Wang L, Wang CH, Chen HY, Li YP. Intravenous chemotherapy for resected gastric cancer: meta-analysis of randomized controlled trials. World J Gastroenterol. 2002;8:1023-8.

27. Hu JK, Li CM, Chen XZ, Chen ZX, Zhou ZG, Zhang B, Chen JP. The effectiveness of intravenous 5-fluorouracil-containing chemotherapy after curative resection for gastric carcinoma: A systematic review of published randomized controlled trials. J Chemother. 2007;19:359-75

28. Janunger KG, Hafström L, Glimelius B. Chemotherapy in gastric cancer: a review and updated meta-analysis. Eur J Surg. 2002;168:597-608.

29. Jemal A, Bray F, Center MM, Ferlay J, Ward E, Forman D. Global cancer statistics CA Cancer J Clin. 2011;61:69-90.

30. Jeung HC, Rha SY, Shin SJ, Ahn JB, Roh JK, Park CH, Noh SH, Chung HC Postoperative adjuvant chemotherapy of gastric cancer: scrutiny into the clinica evidence based on quality assessment of medical literature of randomized controlled trials. Cancer Chemother Pharmacol. 2009;63:919-27.

31. Kilickap S, Yalcin S, Ates O, Tekuzman G. The first line systemic chemotherapy in metastatic gastric carcinoma: A comparison of docetaxel, cisplatin and fluorouracil (DCF) versus cisplatin and fluorouracil $(\mathrm{CF})$; versus epirubicin, cisplatin and fluorouracil (ECF) regimens in clinical setting. Hepatogastroenterology. 2011:58:208-12.

32. Kulig J, Kolodziejczyk P, Sierzega M, Bobrzynski L, Jedrys J, Popiela T, Dadan J, Drews M, Jeziorski A, Krawczyk M, Starzynska T, Wallner G. Adjuvant chemotherapy with etoposide, adriamycin and cisplatin compared with surgery alone in the treatment of gastric cancer: a phase III randomized, multicenter, clinical trial. Oncology. 2010;78:54-61.

33. Li W, Qin J, Sun YH, Liu TS. Neoadjuvant chemotherapy for advanced gastric cancer: a meta-analysis. World J Gastroenterol. 2010;16:5621-8.

34. Li ZY, Shan F, Zhang LH, Bu ZD, Wu AW, Wu XJ, Zong XL, Wu Q, Ren H, Ji JF. Complications after radical gastrectomy following FOLFOX7 neoadjuvan chemotherapy for gastric cancer. World J Surg Oncol. 2011;9:110.

35. Liu TS, Wang Y, Chen SY, Sun YH. An updated meta-analysis of adjuvant chemotherapy after curative resection for gastric cancer. Eur J Surg Oncol 2008;34:1208-16.

36. Macdonald JS, Smalley SR, Benedetti J, Hundahl SA, Estes NC, Stemmermann GN, Haller DG, Ajani JA, Gunderson LL, Jessup JM, Martenson JA. Chemoradiotherapy after surgery compared with surgery alone for adenocarcinoma of the stomach or gastroesophageal junction. N Engl J Med. 2001;345:725-30.

37. Marutsuka T, Shimada S, Shiomori K, Hayashi N, Yagi Y, Yamane T, Ogawa M. Mechanisms of peritoneal metastasis after operation for non-serosa-invasive gastric carcinoma: an ultrarapid detection system for intraperitoneal free cancer cells and a prophylactic strategy for peritoneal metastasis. Clin Cancer Res. 2003;9:678-85

38. Miyazono F, Natsugoe S, Takao S, Tokuda K, Kijima F, Aridome K, Hokita S, Baba M, Eizuru Y, Aikou T. Surgical maneuvers enhance molecular detection of circulating tumor cells during gastric cancer surgery. Ann Surg. 2001;233:189-94. 
39. Muraro CL. Early gastric cancer: contribution to diagnosis and results of surgical treatment. Rev Col Bras Cir. 2003;30:352-8.

40. Nakajima T, Kinoshita T, Nashimoto A, Sairenji M, Yamaguchi T, Sakamoto J, Fujiya T, Inada T, Sasako M, Ohashi Y and Group, National Surgical Adjuvant Study of Gastric Cancer. Randomized controlled trial of adjuvant uracil-tegafur versus surgery alone for serosa-negative, locally advanced gastric cancer. Br J Surg. 2007;94:1468-76.

41. Nashimoto A, Nakajima T, Furukawa H, Kitamura M, Kinoshita T, Yamamura Y, Sasako M, Kunii Y, Motohashi H, Yamamoto S and Gastric Cancer Surgical Study Group, Japan Clinical Oncology Group. Randomized trial of adjuvant chemotherapy with mitomycin, fluorouracil, and cytosine arabinoside followed by oral fluorouracil in serosa-negative gastric cancer: Japan Clinical Oncology Group 9206-1. J Clin Oncol. 2003;21:2282-7.

42. Nitti D, Wils J, Dos Santos JG, Fountzilas G, Conte PF, Sava C, Tres A, Coombes RC, Crivellari D, Marchet A, Sanchez E, Bliss JM, Homewood J, Couvreur ML, Hall E, Baron B, Woods E, Emson M, Van Cutsem E, Lise M, EORTC GI Group; ICCG. Randomized phase III trials of adjuvant FAMTX or FEMTX compared with surgery alone in resected gastric cancer. A combined analysis of the EORTC GI Group and the ICCG. Ann Oncol. 2006;17:262-9.

43. Oba K, Morita S, Tsuburaya A, Kodera Y, Kobayashi M, Sakamoto J. Efficacy of adjuvant chemotherapy using oral fluorinated pyrimidines for curatively resected gastric cancer: a meta-analysis of centrally randomized controlled clinical trials in Japan. J Chemother. 2006;18:311-7.

44. Oba K. Efficacy of adjuvant chemotherapy using tegafur-based regimen for curatively resected gastric cancer: update of a meta-analysis. Int J Clin Oncol. 2009; 14:85-9.

45. Ohtsu A, Yoshida S, Saijo N. Disparities in gastric cancer chemotherapy between the East and West. J Clin Oncol. 2006;24:2188-96.

46. Ohtsu A. Diverse eastern and Western approaches to the management of gastric cancer. Gastrointest Cancer Res. 2007;1:S10-5.

47. Panzini I, Gianni L, Fattori PP, Tassinari D, Imola M, Fabbri P, Arcangeli V, Drudi G, Canuti D, Fochessati F, Ravaioli A. Adjuvant chemotherapy in gastric cancer: a meta-analysis of randomized trials and a comparison with previous meta-analyses. Tumori. 2002;88:21-7.

48. Persiani R, Rausei S, Pozzo C, Biondi A, Barone C, Cananzi FC, Schinzari G, D'Ugo D. 7-Year survival results of perioperative chemotherapy with epidoxorubicin, etoposide, and cisplatin (EEP) in locally advanced resectable gastric cancer: up-to-date analysis of a phase-II study. Ann Surg Oncol. 2008;15:2146-52.

49. Popiela T, Kulig J, Czupryna A, Szczepanik AM, Zembala M. Efficiency of adjuvant immunochemotherapy following curative resection in patients with locally advanced gastric cancer. Gastric Cancer. 2004;7:240-5.

50. Sakuramoto S, Sasako M, Yamaguchi T, Kinoshita T, Fujii M, Nashimoto A, Furukawa H, Nakajima T, Ohashi Y, Imamura H, Higashino M, Yamamura Y, Kurita A, Arai K; ACTS-GC. Group. Adjuvant chemotherapy for gastric cancer with S-1, an oral fluoropyrimidine. N Engl J Med. 2007;357:1810-20.

51. Sasako M, Sakuramoto S, Katai H, Kinoshita T, Furukawa H, Yamaguchi T, Nashimoto A, Fujii M, Nakajima T, Ohashi Y. Five-year outcomes of a randomized phase III trial comparing adjuvant chemotherapy with S-1 versus surgery alone in stage II or III gastric cancer. J Clin Oncol. 2011;29:4387-93.

52. Schuhmacher C, Gretschel S, Lordick F, Reichardt P, Hohenberger W, Eisenberger CF, Haag C, Mauer ME, Hasan B, Welch J, Ott K, Hoelscher A, Schneider PM, Bechstein W, Wilke H, Lutz MP, Nordlinger B, Van Cutsem E, Siewert JR, Schlag PM. Neoadjuvant chemotherapy compared with surgery alone for locally advanced cancer of the stomach and cardia: European Organisation for Research and Treatment of Cancer randomized trial 40954. J Clin Oncol. 2010;28:5210-8.
53. Shitara K, Sawaki A, Matsuo K, Kondo C, Takahari D, Ura T, Tajika M, Niwa Y, Muro K. A retrospective comparison of S-1 plus cisplatin and capecitabine plus cisplatin for patients with advanced or recurrent gastric cancer. Int $\mathbf{J}$ Clin Oncol. 2012. [Epub ahead of print].

54. Songun I, Keizer HJ, Hermans J, Klementschitsch P, de Vries JE, Wils JA, van der Bijl J, van Krieken JH, van de Velde CJ. Chemotherapy for operable gastric cancer: results of the Dutch randomised FAMTX trial. The Dutch Gastric Cancer Group (DGCG). Eur J Cancer. 1999;35:558-62.

55. Sumpter K, Harper-Wynne C, Cunningham D, Rao S, Tebbutt N, Norman AR, Ward C, Iveson T, Nicolson M, Hickish T, Hill M, Oates J. Report of two protocol planned interim analyses in a randomised multicentre phase III study comparing capecitabine with fluorouracil and oxaliplatin with cisplatin in patients with advanced oesophagogastric cancer receiving ECF. Br J Cancer. 2005;92:1976-83.

56. Sun P, Xiang JB, Chen ZY. Meta-analysis of adjuvant chemotherapy after radical surgery for advanced gastric cancer. Br J Surg. 2009;96:26-33.

57. Van Cutsem E, Hoff PM, Harper P, Bukowski RM, Cunningham D, Dufour P, Graeven U, Lokich J, Madajewicz S, Maroun JA, Marshall JL, Mitchell EP, Perez-Manga G, Rougier P, Schmiegel W, Schoelmerich J, Sobrero A, Schilsky RL. Oral capecitabine vs intravenous 5-fluorouracil and leucovorin: integrated efficacy data and novel analyses from two large, randomised, phase III trials. $\mathrm{Br}$ J Cancer. 2004;90:1190-7.

58. Van Cutsem E, Moiseyenko VM, Tjulandin S, Majlis A, Constenla M, Boni C, Rodrigues A, Fodor M, Chao Y, Voznyi E, Risse ML, Ajani JA; V325 Study Group. Phase III study of docetaxel and cisplatin plus fluorouracil compared with cisplatin and fluorouracil as first-line therapy for advanced gastric cancer: a report of the V325 Study Group. J Clin Oncol. 2006;24:4991-7.

59. Van Cutsem E, Van de Velde C, Roth A, Lordick F, Köhne CH, Cascinu S, Aapro M, European Organisation for Research and Treatment of Cancer (EORTC)-gastrointestinal cancer group. Expert opinion on management of gastric and gastro-oesophageal junction adenocarcinoma on behalf of the European Organisation for Research and Treatment of Cancer (EORTC)-gastrointestinal cancer group. Eur J Cancer. 2008;44:182-94.

60. Vinagre RM, Campos BP, Sousa RM. Case study of stomach adenocarcinoma conducted at a cancer referral hospital in northern Brazil. Arq Gastroenterol. 2012;49:125-9.

61. Yamaguchi K, Sawaki A, Doi T, Satoh T, Yamada Y, Omuro Y, Nishina T, Boku N, Chin K, Hamamoto Y, Takiuchi H, Komatsu Y, Saji S, Koizumi W, Miyata Y, Sato A, Baba E, Tamura T, Abe T, Ohtsu A. Efficacy and safety of capecitabine plus cisplatin in Japanese patients with advanced or metastatic gastric cancer: subset analyses of the AVAGAST study and the ToGA study. Gastric Cancer. 2013;16:183-4

62. Ychou M, Boige V, Pignon JP, Conroy T, Bouché O, Lebreton G, Ducourtieux M, Bedenne L, Fabre JM, Saint-Aubert B, Genève J, Lasser P, Rougier P. Perioperative chemotherapy compared with surgery alone for resectable gastroesophageal adenocarcinoma: an FNCLCC and FFCD multicenter phase III trial. J Clin Oncol. 2011;29:1715-21.

63. Zhao SL, Fang JY. The role of postoperative adjuvant chemotherapy following curative resection for gastric cancer: a meta-analysis. Cancer Invest. 2008;26:317-25.

64. Zilberstein B, Jacob CE, Cecconello I. Gastric cancer trends in epidemiology. Arq Gastroenterol. 2012;49:177-8. 